\title{
Establishment and Implementation of Source Water Implementation Plan for Water Treatment Plants in Taiwan
}

\author{
E.-E. Chang'; Yi-Li Lin²; and Pen-Chi Chiang ${ }^{3}$
}

\begin{abstract}
In accordance with the source water implementation plan rule (SWIPR) in Taiwan, water treatment plants (WTPs) with source water parameters exceeding the source water quality standards are required to submit a source water implementation plan to improve the source water and drinking water quality. In this study, the SWIPR was analyzed, and the concept of comprehensive performance evaluation (CPE) was applied for upgrading the performance of WTPs. Three WTPs [Da-Nan WTP (Type 1), Liu-Du WTP (Type 2), and Chen-Chin-Lake WTP (Type 3)] were selected as demonstration projects. A CPE team was established to evaluate the operations of these WTPs and make recommendations for improving the performance of the WTPs to achieve the drinking water standards. This paper describes the analysis and recommendations of the CPE team.
\end{abstract}

DOI: 10.1061/(ASCE)1090-025X(2007)11:1(2)

CE Database subject headings: Water quality; Water treatment plants; Taiwan.

\section{Introduction}

Population growth and industrial development are two major factors causing increases in water consumption in Taiwan. Further, the quantity and quality of source water are deteriorating because of overuse and heavy loading of point and nonpoint pollution, such as human activities, domestic wastewaters, and agricultural discharges. To protect water resources from deterioration and to protect public health, it is important to establish and enforce source water and drinking water quality standards.

As Taiwan has limited water sources, it is crucial to protect and improve the existing source water quality and conserve the water resource. For those water treatment plants (WTPs) that have poor source water quality, along with their parent company, Taiwan Water Company, a source water implementation plan (SWIP) is required to be submitted to the Taiwan Environmental Protection Agency (EPA). Along with the submittal of the SWIP, an evaluation and modification program of the existing water treatment units based on the concept of comprehensive performance evaluation (CPE) must be implemented. The CPE is a process for evaluating a WTP's design capabilities and associated administrative, operational, and maintenance practices of the facility in a systematic way to achieve optimum performance of the facility (USEPA 1998). After comprehensive evaluation of the

\footnotetext{
${ }^{1}$ Dept. of Biochemistry, Taipei Medical Univ., 250 Wu-Hsing St., Taipei, Taiwan, Republic of China.

${ }^{2}$ Graduate Institute of Environmental Engineering, National Taiwan Univ., 71 Chou-Shan Rd., Taipei, Taiwan, Republic of China (corresponding author). E-mail: f88541104@ntu.edu.tw

${ }^{3}$ Graduate Institute of Environmental Engineering, National Taiwan Univ., 71 Chou-Shan Rd., Taipei, Taiwan, Republic of China.

Note. Discussion open until June 1, 2007. Separate discussions must be submitted for individual papers. To extend the closing date by one month, a written request must be filed with the ASCE Managing Editor. The manuscript for this paper was submitted for review and possible publication on May 9, 2006; approved on May 12, 2006. This paper is part of the Practice Periodical of Hazardous, Toxic, and Radioactive Waste Management, Vol. 11, No. 1, January 1, 2007. CASCE, ISSN 1090-025X/2007/1-2-10/\$25.00.
}

facility, the CPE expert team recommends an improvement plan which should be implemented by the WTP's staffs. This evaluation process is intended to provide recommendations to the water industry for upgrading their existing facilities or improving the treatment processes if the source water quality at those facilities cannot meet the standards.

The objective of this research is to analyze the general principles of the source water implementation plan rule (SWIPR) for protecting the source water as well as ensuring the safe drinking water in Taiwan. The source water and drinking water quality standards in Taiwan also were reviewed. Three WTPs were chosen as demonstration projects and were assessed in accordance with the CPE process to comply with SWIPR. The implementation process and assessment outcomes for those WTPs were revealed throughout this investigation.

\section{General Principles of the Source Water Implementation Plan Rule}

In Taiwan, a WTP is required to produce safe drinking water and to protect source water entering into the treatment plan (Fig. 1). Therefore, it is imperative for WTPs to establish procedures to implement the source water and drinking water quality standards. In Taiwan, the SWIPR was promulgated to integrate the CPE technique into source water protection. The history of the Taiwanese water quality standards and implementation of SWIPR at three demonstration sites are shown in the following.

\section{Drinking Water Quality Standards}

The current Drinking Water Management Act was promulgated by the Taiwanese Presidential Office and became effective in November 1972, as amended in May 1997. Article 6 of the Act requires that surface water and groundwater meet drinking water quality standards prior to being used for drinking water. 


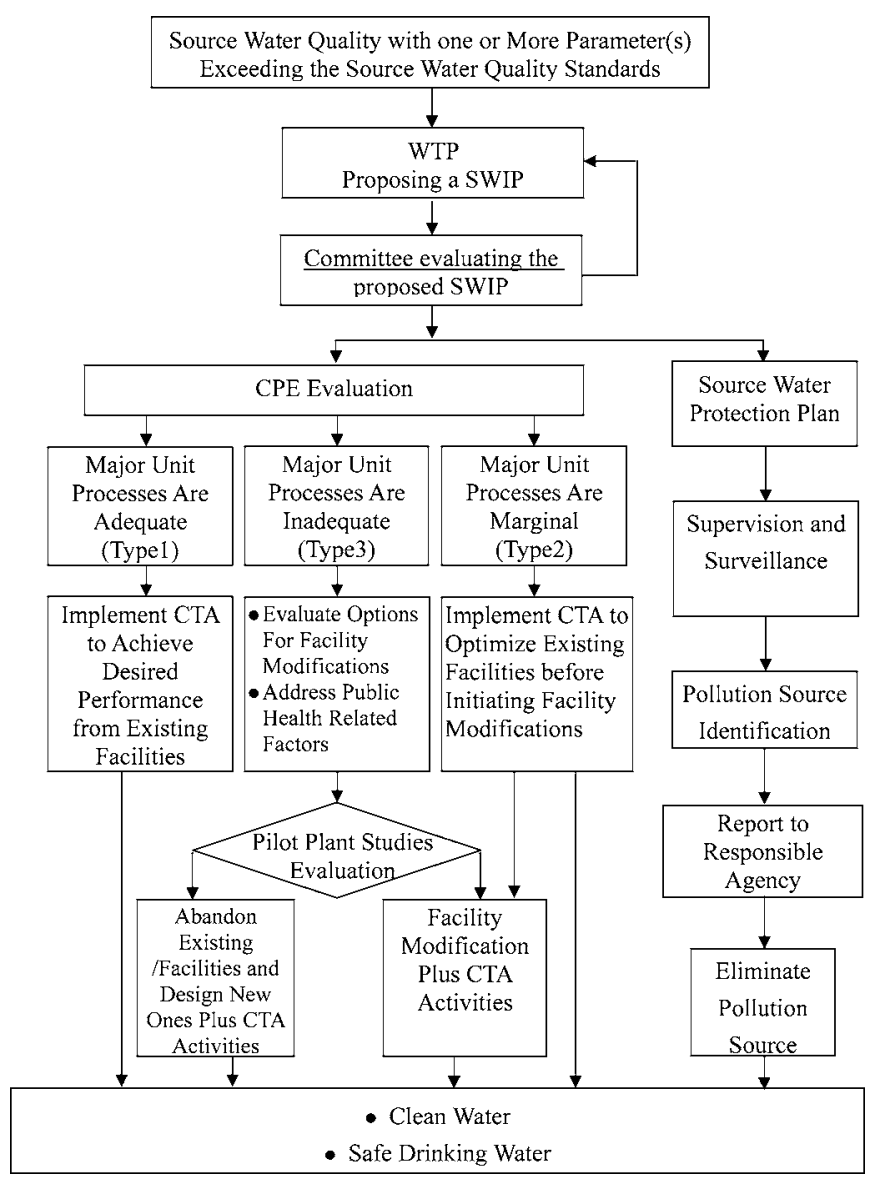

Fig. 1. Operational procedure for a WTP to excuse a SWIP

Drinking water quality standards that were enacted in Taiwan in 1972 included 37 bacteriological, chemical, physical, and radionucleic parameters (Yeh et al. 1997). The latest revision contains 52 regulated parameters that are classified into three categories: (1) microbial parameters, including coliform group and total bacterial count; (2) physical parameters, including odor, turbidity, and color; and (3) chemical parameters including volatile organic compounds, synthetically organic compounds, and heavy metals. The latest revisions to the drinking water quality standards were incorporated in the regulations implementing the Act in February 1998.

\section{Source Water Quality Standards}

The Taiwanese source water quality standards were promulgated by the Taiwan EPA in 1997. A comparison of source water quality criteria/standards in various nations is shown in Table 1 (EEC 1975; EHD 2003; NHMRC 1996; USEPA 2004; Chang et al. 2005). If a WTP is found to use unacceptable source water, it may be subject to a fine or halt the source water usage. Halting source water usage was not a viable option because of difficulty in obtaining new drinking water sources. Therefore, the Taiwan EPA promulgated SWIPR to guide WTPs with poor source water in protecting source water quality and improving the performance of existing water treatment facilities in providing safe drinking water.

\section{Source Water Implementation Plan Rule}

The SWIPR was promulgated in November 1997 by the Taiwan EPA. The purpose of this rule is to protect source water and adopt the CPE process suggested by the USEPA to improve WTP performance (1991). The CPE technique uses a rating system to classify each major treatment process as Types 1, 2, or 3 (USEPA 1998). The methodology to determine the process type is based on the capability of the specific unit process in treating water. A unit process would be rated Type 1 if its operating capacity exceeds the peak instantaneous operating flow rate; Type 2 if its capacity is $80-100 \%$ of the peak flow; or Type 3 if its operating capacity is less than $80 \%$ of the peak flow. The performance problems associated with Type 1 plants are likely to be related to plant operation, maintenance, and/or administration, which may be improved by technical assistance. Type 2 plants need to provide minor process improvements to meet performance goals. Type 3 facilities require major modifications to achieve performance objectives. A comprehensive assessment of the facility's operating capacity is made by the CPE team, and the performance-limiting factors are determined in order to implement the comprehensive technical assistance (CTA) technique to achieve the desired water quality at optimal performance. After completing the CPE process, a CTA may be implemented for facility improvement in the WTP.

The SWIPR requires that the WTP manager submit and implement the SWIP. The SWIP is for upgrading the existing facilities or installing advanced treatment processes when the quality of the source water entering the plant is not in compliance with the source water quality standards. The SWIP needs to include the following items:

1. Basic information regarding the WTP facility;

2. Population of the region and the amount of water supplied;

3. Inspection data that include statistical tables and figures, for the water quality parameters not meeting the source water quality standards; and

4. Inspection plans and emergency response plans during the period of executing the SWIP.

When executing the SWIP, the WTP manager is required to submit a water quality report to evaluate if the water quality parameter(s) exceeds the source water quality standards in five consecutive inspections.

If any parameter of the source water quality is not in compliance with the source water quality standards after the fifth inspection, the plant manager will be fined between 60,000 and 600,000 NT dollars (approximately 1,890-18,900 USD); or the usage of the source water will be halted. The source water is allowed to be used again only after the SWIP is approved by the Taiwan EPA.

Taiwan EPA invites experts, scholars, and related institutions to form a review committee to evaluate the proposed SWIP. If the proposed plan is approved by the Taiwan EPA, the water plant manager must execute the implementation plan and submit progress reports to the Taiwan EPA and the local responsible agency. For a proposed SWIP with an execution period of less than six months, progress reports must be submitted monthly; for a proposed SWIP with an execution period of more than six months, progress reports must be submitted every three months. If necessary, the Taiwan EPA or the local responsible agency may invite the reviewers to audit the achievements on site. If the evaluation cannot meet the requirements of SWIPR, the previously approved SWIP will be revoked and the WTP will be required to shut down. 
Table 1. Comparison of Source Water Quality Criteria/Standards in Various Nations

\begin{tabular}{|c|c|c|c|c|c|c|c|}
\hline Parameter units & USEPA $^{\mathrm{a}}$ & $\begin{array}{l}\text { Alberta, } \\
\text { Canada }\end{array}$ & $\begin{array}{l}\text { EC } \\
\text { (A1) }\end{array}$ & Japan & Australia & $\begin{array}{c}\text { Germany } \\
\text { (Rhine River) }\end{array}$ & Taiwan \\
\hline \multicolumn{8}{|l|}{ I. Microorganisms } \\
\hline $\begin{array}{l}\text { Total coliforms } \\
\text { (CFU/100 mL) }\end{array}$ & 20,000 & 5,000 & - & 5,000 & $<10$ & - & 20,000 \\
\hline Fecal coliforms (CFU/100 mL) & 2,000 & 1,000 & - & - & $\mathrm{ND}^{\mathrm{d}}$ & - & - \\
\hline \multicolumn{8}{|l|}{ II. Physical parameters } \\
\hline Color (CU) & - & $\leqq 30$ & 20 & 10 & 15 & 0.5 & - \\
\hline $\mathrm{pH}$ & $5.0-9.0$ & $6.5-8.5$ & - & $6.5-8.5$ & $6.5-8.5$ & $6.5-8.5$ & - \\
\hline \multicolumn{8}{|l|}{ III. Inorganics } \\
\hline As $(\mu \mathrm{g} / \mathrm{L})$ & 10 & 10 & 50 & 10 & 1 & 5 & 50 \\
\hline $\mathrm{Ba}(\mu \mathrm{g} / \mathrm{L})$ & 1,000 & 1,000 & 50 & - & 1 & 700 & - \\
\hline $\mathrm{Cr}(\mu \mathrm{g} / \mathrm{L})$ & - & 20 & 50 & 50 & 0.01 & 25 & 50 \\
\hline $\mathrm{Cd}(\mu \mathrm{g} / \mathrm{L})$ & - & 10 & 5 & 10 & 0.06 & 3 & 10 \\
\hline $\mathrm{Hg}(\mu \mathrm{g} / \mathrm{L})$ & - & 0.1 & 1 & 0.5 & 0.06 & 0.5 & 2 \\
\hline $\mathrm{Pb}(\mu \mathrm{g} / \mathrm{L})$ & - & 50 & 50 & 10 & 1.0 & 5 & 50 \\
\hline $\operatorname{Se}(\mu \mathrm{g} / \mathrm{L})$ & 170 & 10 & 10 & 10 & 5 & 5 & 50 \\
\hline $\mathrm{Ag}(\mu \mathrm{g} / \mathrm{L})$ & - & 50 & - & - & 0.02 & - & - \\
\hline $\mathrm{Cu}(\mu \mathrm{g} / \mathrm{L})$ & 1,300 & 20 & 50 & 1,000 & 1.0 & - & - \\
\hline $\mathrm{Fe}(\mu \mathrm{g} / \mathrm{L})$ & 300 & 300 & 300 & 300 & - & - & - \\
\hline $\operatorname{Mn}(\mu \mathrm{g} / \mathrm{L})$ & 50 & 50 & - & 20 & 1,200 & - & - \\
\hline $\mathrm{Zn}(\mu \mathrm{g} / \mathrm{L})$ & 7,400 & 50 & 3,000 & 1,000 & 2.4 & - & - \\
\hline $\mathrm{NH}_{3}-\mathrm{N}(\mathrm{mg} / \mathrm{L})$ & - & $1(\mathrm{TKN})$ & - & 0.5 & 0.32 & 0.3 & 1 \\
\hline $\mathrm{Cl}^{-}(\mathrm{mg} / \mathrm{L})$ & - & 1.5 & - & 200 & 0.0004 & 100 & - \\
\hline $\mathrm{CN}^{-}(\mu \mathrm{g} / \mathrm{L})$ & 700 & 15 & 50 & 10 & 0.004 & 25 & - \\
\hline $\mathrm{NO}_{3}^{-}(\mathrm{mg} / \mathrm{L})$ & 10 & - & 50 & 9 & 0.00017 & - & - \\
\hline $\mathrm{SO}_{4}^{2-}(\mathrm{mg} / \mathrm{L})$ & - & $0.05\left(\mathrm{~S}^{2-}\right)$ & 250 & - & 0.0005 & 100 & - \\
\hline \multicolumn{8}{|l|}{ IV. Organics } \\
\hline Surfactants (MBAS) $(\mu \mathrm{g} / \mathrm{L})$ & - & - & - & 500 & - & - & - \\
\hline Phenol ( $\mu g / L)$ & 21,000 & 5 & 1 & 5 & 85 & - & - \\
\hline Total pesticides $(\mu \mathrm{g} / \mathrm{L})$ & - & - & 0.2 & - & - & 50 & - \\
\hline $\mathrm{COD}(\mathrm{mg} / \mathrm{L})$ & - & - & - & $3\left(\mathrm{KMnO}_{4}\right)$ & - & - & $25\left(\mathrm{~K}_{2} \mathrm{Cr}_{2} \mathrm{O}_{7}\right)$ \\
\hline $\mathrm{PCB}^{\mathrm{b}}(\mu \mathrm{g} / \mathrm{L})$ & 0.000064 & - & - & $\mathrm{ND}^{\mathrm{d}}$ & - & - & - \\
\hline $\mathrm{PAHs}^{\mathrm{c}}(\mu \mathrm{g} / \mathrm{L})$ & - & - & 0.2 & - & - & 0.1 & - \\
\hline TOC (mg/L) & - & - & - & - & - & 3 (DOC) & 4 \\
\hline
\end{tabular}

aSEPA national recommended water quality criteria: 2004, for consumption of "water+organism.'

${ }^{\mathrm{b}}$ Polychlorinated biphenyls.

${ }^{\mathrm{c}}$ Polycyclic aromatic hydrocarbon.

${ }^{\mathrm{d}}$ Not detectable.

Fig. 1 shows the operational procedures for a WTP to execute an SWIP.

\section{Methodology}

Model Development and Applications for Balancing THMs Formation and Disinfection Efficiency in Liu-Du WTP

A relatively simple model proposed by our previous study (Chiang et al. 1997) derived from former researchers (Morris and Baum 1977; Qualls and Johnson 1983; Rook 1977) can be used for predicting disinfection efficiency as well as trihalomethanes (THM) formation at the Liu-Du WTP for executing the action recommended by the CPE team. In this model, a dispersion model, disinfection kinetics, and THM formation kinetics were combined together. The average disinfection efficiency with given exit age distribution function and batch kinetics can be integrated as

$$
\begin{aligned}
\left(1-\frac{\mathrm{N}}{\mathrm{N}_{0}}\right) \times 100 \% \\
=\left(1-\int_{0}^{\infty}\left[\frac{\mathrm{N}}{\mathrm{N}_{0}}\right]_{\mathrm{batch}} E_{\theta} d \theta\right) \times 100 \% \\
=\left\{1-\left[\int_{0}^{b / C T} \frac{1}{\sqrt{4 \pi \theta d}} \exp \left(\frac{-(1-\theta)^{2}}{4 \theta d}\right)\right.\right. \\
\left.\left.+\int_{b / C T}^{\infty}\left(\frac{b}{C T}\right)^{n} \frac{1}{\sqrt{4 \pi \theta d}} \exp \left(\frac{-(1-\theta)^{2}}{4 \theta d}\right)\right] d \theta\right\} \times 100 \%
\end{aligned}
$$

where $\mathrm{d}=0.14 \mathrm{~kW} / \mathrm{L}$. The residual free chlorine and THMs forma- 
Table 2. Background Information on Three Chosen Demonstration WTPs in Taiwan

\begin{tabular}{|c|c|c|c|c|}
\hline WTP & Capacity (CMD) & $\begin{array}{l}\text { Parameters } \\
\text { exceeding the } \\
\text { source water } \\
\text { quality } \\
\text { standards }\end{array}$ & $\begin{array}{c}\text { Treatment } \\
\text { process }^{\mathrm{a}}\end{array}$ & Pollution source \\
\hline Da-Nan & 280,000 & Total coliforms & $\mathrm{M} \rightarrow \mathrm{C} \rightarrow \mathrm{S} \rightarrow \mathrm{F}$ & $\begin{array}{l}\text { Da-Han River is polluted by the discharge of domestic } \\
\text { sewage, sandstone wastewater, industrial wastewater, waste } \\
\text { discharge and pig farm wastewater. }\end{array}$ \\
\hline Liu-Du & 24,500 & Total coliforms & $\mathrm{H} \rightarrow \mathrm{C} \rightarrow \mathrm{S} \rightarrow \mathrm{F}$ & $\begin{array}{l}\text { Ji-Long River is polluted by the discharge of domestic } \\
\text { sewage. }\end{array}$ \\
\hline Chen-Chin-Lake & 400,000 & $\begin{array}{l}\text { Total hardness, } \\
\qquad \mathrm{NH}_{3}-\mathrm{N}\end{array}$ & $\mathrm{M} \rightarrow \mathrm{C} \rightarrow \mathrm{S} \rightarrow \mathrm{F}$ & $\begin{array}{l}\text { Kaopin River is polluted by livestock wastewater from hog } \\
\text { farms, domestic sewage, industrial wastewater, landfill } \\
\text { leachout, and NPS pollutants from agriculture areas. Besides, } \\
\text { the unpleasant taste and odor of tap water caused by the high } \\
\text { organic matter and ammonia nitrogen in source water are } \\
\text { always complained by the local residents. }\end{array}$ \\
\hline
\end{tabular}

$\overline{\mathrm{a}} \mathrm{H}=$ hydraulic jump tank; $\mathrm{M}=$ rapid mixing tank; $\mathrm{C}=$ coagulation basin; $\mathrm{S}=$ sedimentation tank; and $\mathrm{F}=$ rapid filtration basin.

tion in a continuous flow-through reactor can be obtained by

$$
\begin{aligned}
\left(\frac{\left[\mathrm{Cl}_{2}\right]}{\left[\mathrm{Cl}_{2}\right]_{0}}\right)_{\text {batch }} & =\int_{0}^{\infty}\left(\frac{\left[\mathrm{Cl}_{2}\right]}{\left[\mathrm{Cl}_{2}\right]_{0}}\right)_{\text {batch }} E_{\theta} d \theta \\
& =\int_{0}^{\infty} \frac{1}{\sqrt{4 \pi \theta d}} \exp \left(\frac{-(1-\theta)^{2}}{4 \theta d}\right) \exp \left(-k_{1} T \theta[\mathrm{TOC}]\right) d \theta
\end{aligned}
$$

$$
\begin{aligned}
{[\mathrm{THMs}]=} & \int_{0}^{\infty}[\mathrm{THMs}]_{\mathrm{batch}} E_{\theta} d \theta=\int_{0}^{\infty} k_{2}[\mathrm{TOC}]^{m} \times T \times\left[\mathrm{Cl}_{2}\right]_{0} \\
& \times \frac{1}{\sqrt{4 \pi \theta d}} \exp \left(\frac{-(1-\theta)^{2}}{4 \theta d}\right) \exp \left(-k_{1} T \theta[\mathrm{TOC}]\right) d \theta
\end{aligned}
$$

In our previous research, the value of $b=0.3, n=2$ (Chiang et al. 1997), $k=5, \quad k_{1}=4.17 \times 10^{-4} \mathrm{~L} / \mathrm{mg} \mathrm{min,} m=3$, and $k_{2}=0.0152(\mathrm{~L} / \mathrm{mg}) \mathrm{m} \min$ (Lou and Chiang 1994).

\section{Analytical Methods}

All of the water quality parameters, such as turbidity, DOC, $\mathrm{pH}$, total coliforms, and THMs, were measured for the water samples, followed by the QA/QC programs included in the Standard Methods (APHA 1998).

\section{Demonstration Projects of SWIP Implementations}

Three WTPs participated in SWIP demonstration projects. A committee reviewed each of the WTP's SWIP and provided comments to the WTPs for implementation to improve the plants' performance. The details of the implementation for each WTP are described in the following. The first plant, Da-Nan WTP (classified as Type 1), is the major WTP in the Tao-Yuan County. The total coliform concentration in the source water of this WTP occasionally does not meet the source water quality standards. The second WTP, the Liu-Du WTP (classified as Type 2), is located in Taipei County, and often has high total coliform concentrations which exceed the source water quality standards. The third WTP, the Chen-Chin-Lake WTP (classified as Type 3), is the major WTP in the Kaohsiung area with total hardness and $\mathrm{NH}_{3}-\mathrm{N}$ not meeting the source water quality standards. The treatment processes and pollution sources for these three WTPs are summarized in Table 2 .

\section{Type 1: Da-Nan WTP}

Approximately 600,000 people live in the catchment areas of the Da-Han River which provides source water to the Da-Nan WTP. The designed treatment capacity is 250,000 CMD (cubic meters per day), and the water production rate is 280,000 CMD. The average water quality data of the source water is shown in Table 3. The occurrence percentage of source water turbidity below 100 NTU is $92.9 \%$ from December 2000 to May 2002 (shown in Fig. 2). Extraordinarily high values of turbidity in source water were observed after heavy rainfall caused by typhoons. The extraordinarily poor condition of the source water prevented the coagulation process from removing turbidity to meet the regulatory limit. This condition resulted in a $3.6 \%$ of turbidity in clean water which does not meet the standard value of 2 NTU (shown in Fig. 3). The concentration profiles of total coliforms in source water are shown in Fig. 4. The profiles indicated that a total of

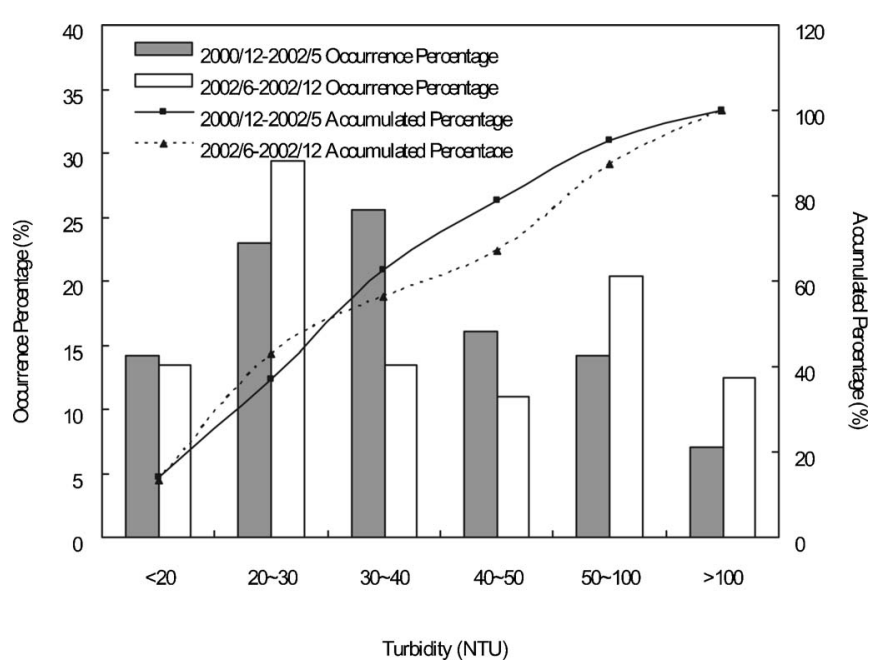

Fig. 2. Turbidity of source water utilized by the Da-Nan WTP from December 2000 to December 2002 
Table 3. Water Quality Data for the Da-Nan and Liu-Du WTPs in the Period of 2000-2002

\begin{tabular}{|c|c|c|c|c|}
\hline \multirow[b]{2}{*}{ Water quality parameters } & \multicolumn{2}{|c|}{ Raw water } & \multicolumn{2}{|c|}{ Finished water } \\
\hline & Da-Nan & Liu-Du & Da-Nan & Liu-Du \\
\hline Turbidity (NTU) & $6.3-2,500$ & $1.2-245$ & $0.2-10$ & $0.2-2.1$ \\
\hline $\mathrm{COD}(\mathrm{mg} / \mathrm{L})$ & $2-10$ & $4-19$ & ND & ND-3 \\
\hline $\mathrm{NH}_{3}-\mathrm{N}(\mathrm{mg} / \mathrm{L})$ & $0-0.2$ & - & ND & - \\
\hline TDS (mg/L) & $100-200$ & - & $100-200$ & - \\
\hline Total hardness (mg/L) & $70-150$ & - & $70-150$ & - \\
\hline Conductivity (mmho/cm) & $200-300$ & - & $200-300$ & - \\
\hline Free chlorine (mg/L) & $<5$ & - & $5-20$ & $0.62-1.40$ \\
\hline TOC (mg/L) & - & $0.54-5.04$ & - & $0.5-1.27$ \\
\hline Fluorescence $\left(\times 10^{-9} \mathrm{M}\right.$ EQ value $)$ & - & $3.23-13.73$ & - & $0.14-1.33$ \\
\hline THMFP $(\mu \mathrm{g} / \mathrm{L})$ & - & $42.11-136.9$ & - & $11.58-53.67$ \\
\hline $\mathrm{UV}_{254}(1 / \mathrm{cm})$ & - & $0.016-0.092$ & - & $0.004-0.010$ \\
\hline Total coliforms (CFU/100 mL) & $300-50,000$ & $2,100-170,000$ & $<1$ & $<1$ \\
\hline
\end{tabular}

$8.3 \%$ of the water quality data exceeded $20,000 \mathrm{CFU} / 100 \mathrm{~mL}$ and $30.8 \%$ exceeded $10,000 \mathrm{CFU} / 100 \mathrm{~mL}$. The value of 10,000 $\mathrm{CFU} / 100 \mathrm{~mL}$ is the anticipated source water quality standard for total coliforms in Taiwan. Based on the previous evidence, the Da-Nan WTP is required to develop and submit a SWIP to the Taiwanese EPA.

After the on-site evaluation of the facilities in the Da-Nan WTP, the plant was classified as Type 1 . The CPE team made several recommendations to improve the plant's performance. First, the particulate active carbon (PAC) mixing intensity in the rapid mixing tank should be checked. Second, the turbidity of treated water from the rapid filtration tank should be decreased. Third, the inspection frequencies for total coliforms in source water, sedimentation effluent, rapid filtration effluent, and clean water should be increased and the disinfection efficiency should be improved.

In response to the $\mathrm{CPE}$ recommendations, the WTP instituted several actions to improve the plant's performance since June 2002. For example, a tracer test with sodium chloride was conducted to ensure that the PAC mixing effect in the hydraulic jump tank performed properly. It was found that the hydraulic jump provided better mixing than the current mixer in the rapid mixing tank. The addition of PAC to the source water may be modified by installing a dosage machine which would provide a fixed amount

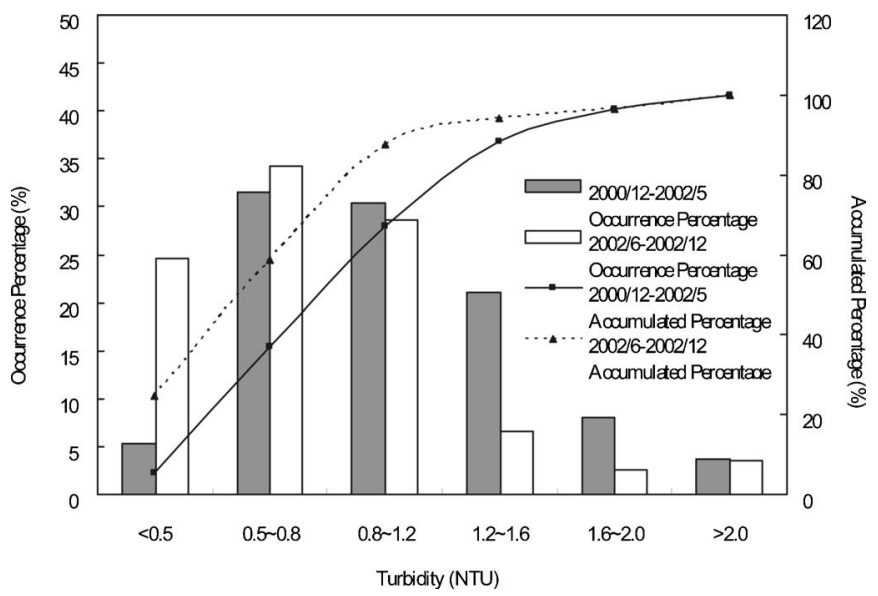

Fig. 3. Turbidity of finished water utilized by the Da-Nan WTP from December 2000 to December 2002 of PAC as compared to manually adding the PAC. To reduce turbidity in rapid filtration effluent, the quality of filter media is examined and replaced gradually. In Fig. 3, it is shown that after the periodic change of filter media, the turbidity of the clean water is $96.5 \%$ accumulative percentage less than the standard value ( 2 NTU) from June to December in 2002. To confirm the disinfection efficiency of total coliforms, the monitoring frequencies of total coliforms in source water, sedimentation effluent, rapid filtration effluent, and clean water were increased from once to twice per week. The pattern of chlorine dosage was modified so that the $C \times T$ (chlorine dose-contact time) value of the disinfection tank was $96.02 \mathrm{mg} \mathrm{min/L} \mathrm{(shown} \mathrm{in} \mathrm{Fig.} \mathrm{5)} \mathrm{as} \mathrm{suggested} \mathrm{by}$ the surface water treatment rule in the United States. Monitoring locations for the THMs (trihalomethanes, the most prevalent disinfection by-products) in clean water also was increased from three points to five points per month. Monitoring results of THMs revealed that all the averaged THM concentrations are below the standard value $(80 \mu \mathrm{g} / \mathrm{L})$, and the concentration of THMs in the distribution system is shown in Fig. 6.

The SWIP also is implemented by patrolling the pollutant sources in the catchment area of source water twice a week, photographing evidence for pollution actions, performing the bioassay tests, and reporting to the responsible agencies.

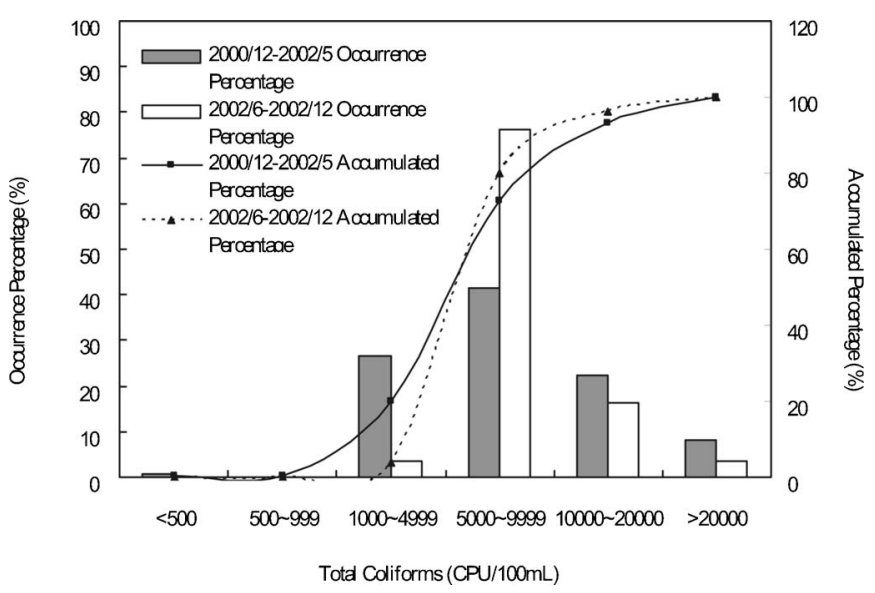

Fig. 4. Concentration profile of total coliforms in source water utilized by the Da-Nan WTP from December 2000 to December 2002 


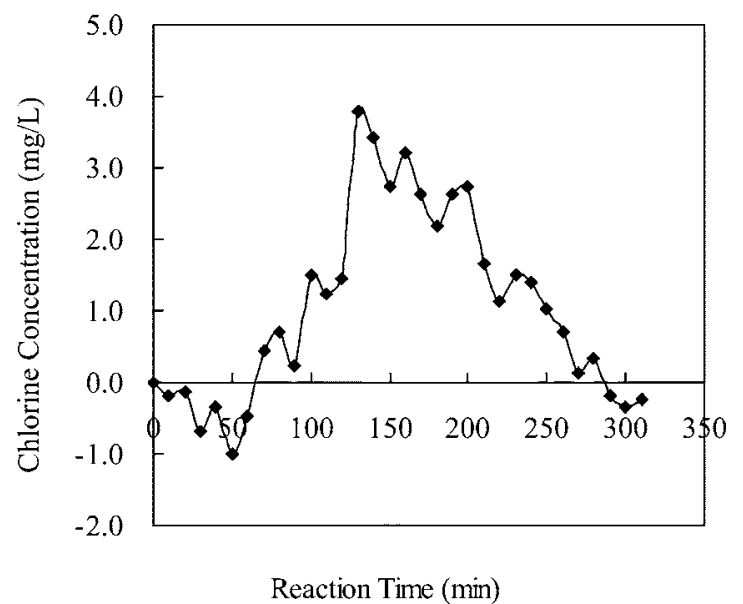

Fig. 5. $C \times T$ value examination experiment of disinfection tank in Da-Nan WTP $\left(T_{10}=124.7 \mathrm{~min}\right.$, residual chlorine $\left.=0.77 \mathrm{mg} / \mathrm{L}\right)$

\section{Type 2: Liu-Du WTP}

The Liu-Du WTP is located near the Ji-Long River, which provides source water to the plant with the average water quality data as shown in Table 3. During the inspection period, the source water was contaminated with total coliform that did not meet the source water quality standards $(20,000 \mathrm{CFU} / \mathrm{mL})$. The total coliform contamination is caused by the discharge of domestic sewage severely polluting the Ji-Long River, especially in dry seasons. The source water also was found to have high values of turbidity (245 NTU) and total organic carbon (TOC) $(5.04 \mathrm{mg} / \mathrm{L})$, which do not meet the source water quality standards (4 mg/L) (Taiwan EPA 2000). As a result, the Liu-Du WTP also was required to develop and submit an SWIP.

As the source water quality cannot be timely improved, the CPE process was performed to evaluate the performance of the existing facilities in the Liu-Du water treatment plant. After the on-site evaluation, the Liu-Du WTP was classified as a Type 2 plant. The CPE team observed several operating problems as follows. First, the removal efficiency of turbidity, which ranged from 55.3 to $86.6 \%$, was not steady. Second, the disinfection efficiency of total coliforms in the finished water tank should be monitored frequently due to high loading of total coliforms.

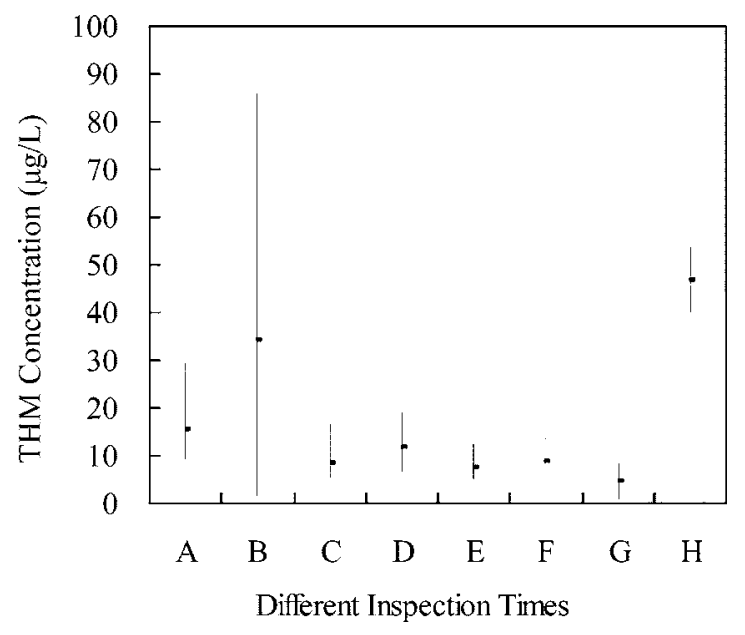

Fig. 6. Concentration of THMs in the distribution system of Da-Nan WTP

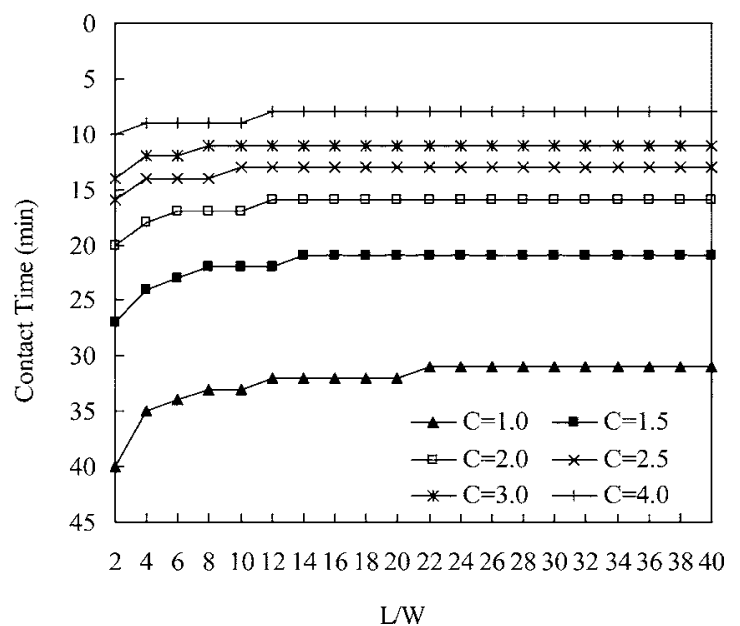

Fig. 7. Relationships among applied chlorine, contact time, and $L / W$ ratio for $99.99 \%$ disinfection efficiency of total coliforms in the rectangular chlorine chamber in the Liu-Du WTP

The CPE team recommended several actions to resolve these problems. These actions are described in the following. To increase turbidity removal, install two plastic cloths that are $1.2 \mathrm{~m}$ in depth. The cloth assists the diversion plate to increase the sedimentation effect of the sedimentation tank and decrease the loading rate of the filtration tank. Further, increase the removing frequency of the scum in the sedimentation tank and install turbidity monitors in each treatment unit.

The disinfection performance curves generated from the disinfection kinetic model [Eqs. (1) and (3)] may be used as the criteria for designing the chlorine contact chamber. Based on the Taiwanese drinking water quality standards, the acceptable disinfection efficiency must be greater than $99.99 \%$ inactivation of total coliforms, and the allowable level of THMs must be less than $80 \mu \mathrm{g} / \mathrm{L}$. These numerical standards may serve as operational guidelines for the plant manager to install the appropriate number of baffles in the chlorine chamber to improve the efficiency of the disinfection process. Fig. 7 may be used to determine the required chlorine doses for a given contact time and a

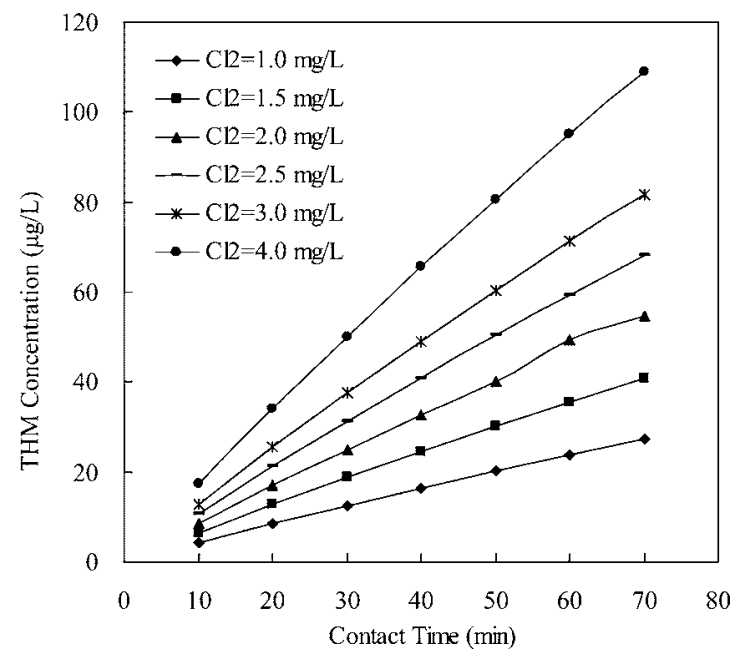

Fig. 8. Effect of applied chlorine on THMs formation of inlet $\mathrm{TOC}=3.0 \mathrm{mg} / \mathrm{L}$ and the rectangular chlorine chamber of $L / W$ ratio $=20$ in the Liu-Du WTP 


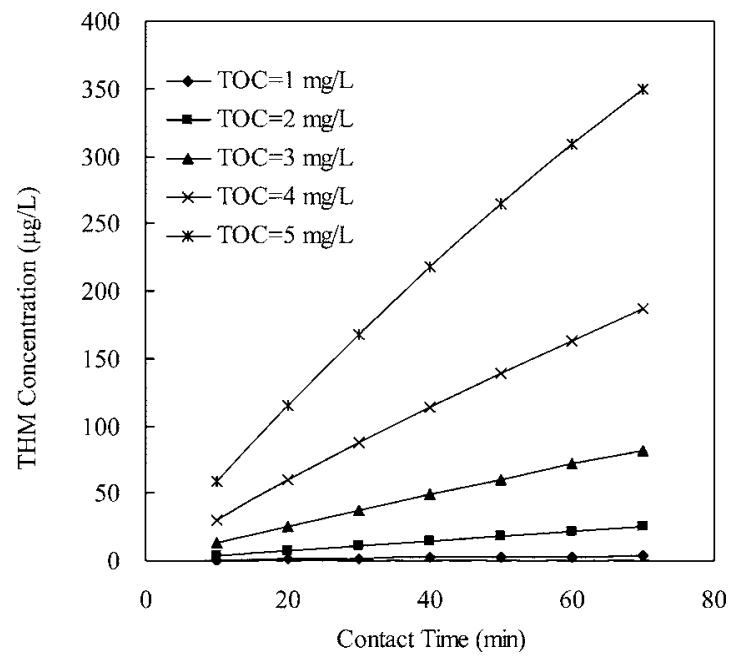

Fig. 9. Effect of TOC on THMs formation for applied chlorine dose $=3.0 \mathrm{mg} / \mathrm{L}$ and the rectangular chlorine chamber of $L / W$ ratio $=20$ in the Liu-Du WTP

given $L / W$ ratio to achieve the $99.99 \%$ disinfection efficiency. Fig. 7 also may aid in designing the chlorine contact chamber and in determining the $L / W$ value and contact time under a given chlorine dose.

Fig. 8 shows the effect of chlorine dose on THMs formation at inlet $\mathrm{TOC}=3.0 \mathrm{mg} / \mathrm{L}$ and the rectangular chlorine chamber at $L / W$ ratio $=20$. To keep the THM formation below $80 \mu \mathrm{g} / \mathrm{L}$ (the current drinking water quality standards) at the Liu-Du WTP, the chlorine dose had to be maintained at below $3 \mathrm{mg} / \mathrm{L}$ for a contact basin with a $L / W$ ratio at 20. Fig. 9 was constructed to predict the effect of TOC on THM formation at the applied chlorine dose $=3.0 \mathrm{mg} / \mathrm{L}$ and the rectangular chlorine chamber of $L / W$ ratio $=20$. Fig. 9 shows that THM concentrations increase linearly with TOC; the higher the TOC, the more rapid the increase in THM formation. To comply with the standard of $80 \mu \mathrm{g} / \mathrm{L}$, the TOC concentration should be maintained below $3 \mathrm{mg} / \mathrm{L}$ before adding disinfectant, which is consistent with results reported by Lou and Chiang (1994). Fig. 10 shows the comparison between the effects of $L / W$ ratio and TOC concentration on THM forma-

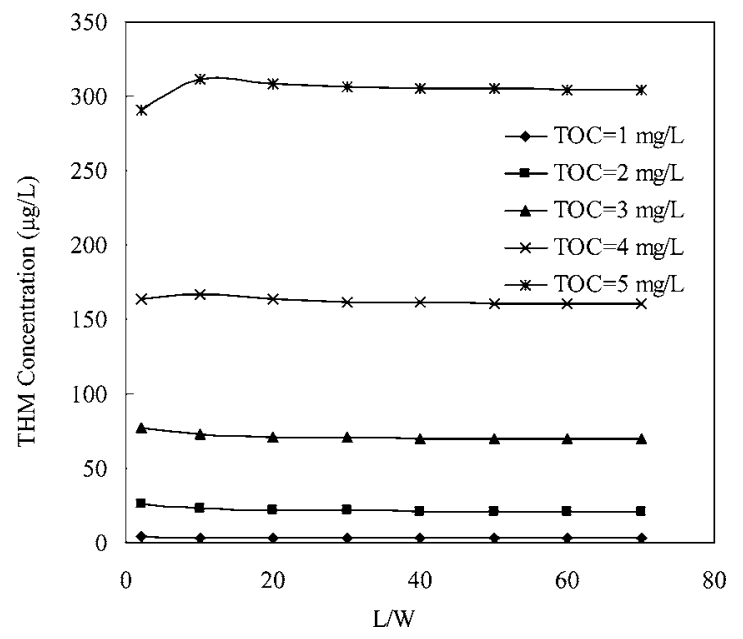

Fig. 10. Comparison between the effects of $L / W$ ratio and TOC concentration on THMs formation for applied chlorine dose $=2.0 \mathrm{mg} / \mathrm{L}$ and contact time of $60 \mathrm{~min}$ in the Liu-Du WTP
Table 4. Average Water Quality Data for the Chen-Chin-Lake WTP from 1996 to 2000

\begin{tabular}{lcc}
\hline Water quality parameters & Source water & Finished water \\
\hline Turbidity $(\mathrm{NTU})$ & 23.8 & 0.95 \\
Bicarbonate $(\mathrm{mg} / \mathrm{L})$ & 152 & 137 \\
Color $(\mathrm{TCU})$ & 13 & $<5$ \\
Total alkali $\left(\mathrm{mg} / \mathrm{L}\right.$ as $\left.\mathrm{CaCO}_{3}\right)$ & 156.9 & 188.9 \\
$\mathrm{pH}$ & 7.8 & 7.3 \\
$\mathrm{Chloride}(\mathrm{mg} / \mathrm{L})$ & 6.9 & 22.3 \\
$\mathrm{Sulfate}(\mathrm{mg} / \mathrm{L})$ & 81.8 & 92.8 \\
$\mathrm{NH}_{3}-\mathrm{N}(\mathrm{mg} / \mathrm{L})$ & 0.36 & 0.08 \\
$\mathrm{NO}_{2}-\mathrm{N}(\mathrm{mg} / \mathrm{L})$ & 0.14 & $\mathrm{ND}$ \\
$\mathrm{NO}_{3}-\mathrm{N}(\mathrm{mg} / \mathrm{L})$ & 1.14 & 1.23 \\
$\mathrm{TDS}(\mathrm{mg} / \mathrm{L})$ & 333 & 394 \\
Total hardness $\left(\mathrm{mg} / \mathrm{L}\right.$ as $\left.\mathrm{CaCO}_{3}\right)$ & 228 & 257 \\
Fe $(\mathrm{mg} / \mathrm{L})$ & 0.31 & 0.05 \\
Mn $(\mathrm{mg} / \mathrm{L})$ & 0.06 & 0.01 \\
Conductivity $(\mu \mathrm{s} / \mathrm{cm})$ & 467 & 569 \\
Total coliforms $(\mathrm{CFU} / 100 \mathrm{~mL})$ & - & - \\
\hline
\end{tabular}

tion for applied chlorine dose $=3.0 \mathrm{mg} / \mathrm{L}$ and contact time of $60 \mathrm{~min}$. From this comparison, it is evident that there is only a small variation in THM formation for $L / W$ ratio ranging from 2 to 70. This concludes that the geometry of a chlorine contactor affects the disinfection efficiency (shown in Fig. 7) but has minimal influence on the formation of THMs. It also may be concluded that reducing TOC prior to chlorine application is a more effective tool for controlling THM formation than altering the geometry $(L / \mathrm{W}$ ratio) of the reactor.

Based on the previous conclusion, the application of chlorine maintained at approximately $1.0 \mathrm{mg} / \mathrm{L}$ level at Liu-Du WTP as the most cost effective method to minimize THM formation and improve the disinfection efficiency. Under these operational conditions, the Liu-Du WTP may maintain an acceptable level of residual chlorine $(0.2-1.0 \mathrm{mg} / \mathrm{L})$ and THMs $(80 \mu \mathrm{g} / \mathrm{L})$.

\section{Type 3: Chen-Chin-Lake WTP}

The Kaopin River provides most of the source water to the Kaoshiung metropolitan area with an average flow rate of 650,000 CMD for 2,370,000 residents. The source water has been seriously contaminated by livestock wastewater from hog farms, domestic sewage, industrial wastewater, landfill leachate, and nonpoint source (NPS) pollutants from agriculture areas, accounting for $52.5,11.2,28.8,2.2$, and $5.3 \%$, respectively, with a total of $23,187 \mathrm{~kg}$ of BOD per day. In the catchment area of the Kaopin River, the Chen-Chin-Lake is the major WTP. Table 4 shows the average water quality data of Chen-Chin-Lake WTP. Although the average $\mathrm{NH}_{3}-\mathrm{N}$ level shown in Table 4 is under $1 \mathrm{mg} / \mathrm{L}$, several unacceptable $\mathrm{NH}_{3}-\mathrm{N}$ levels have been reported. Local residents have complained about the unpleasant taste and odor of tap water. This situation is caused by the high organic matter and ammonia nitrogen in the source water. As a result, the Chen-Chin-Lake WTP was required to develop and submit a SWIP.

The CPE process also was used to evaluate the performance of the existing facilities at the Chen-Chin-Lake WTP. After the on-site evaluation, the Chen-Chin-Lake WTP was classified as a Type 3 plant. The CPE team observed that the performance of the conventional treatment process, i.e., flotation and the coagulation-sedimentation tanks, and floc-forming condition are not satisfactory. Further, the high $\mathrm{NH}_{3}-\mathrm{N}$ caused an overdose of 


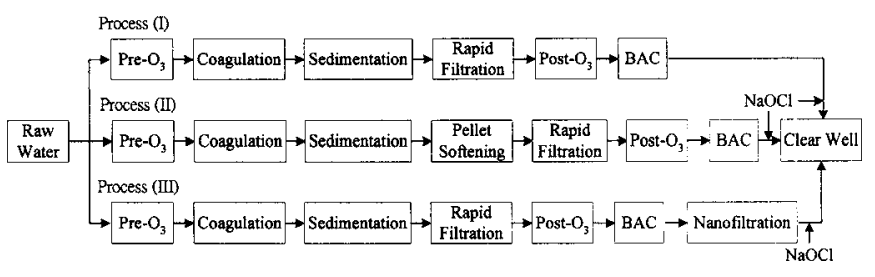

Fig. 11. Processes at the pilot plant in the Chen-Chin-Lake WTP

prechlorination. To alleviate these problems, pilot plant studies on process modifications of the Chen-Chin-Lake WTP were performed and are shown in Fig. 11. Table 5 presents the overall performance evaluation of the selected advanced treatment processes from the aspects of engineering, environment, and economy.

Among the three test processes conducted at the pilot plants, Processes (II) and (III) exhibit greater performance in terms of efficiency, flexibility, and reliability. As Process (II) is more economical than Process (III) for meeting the drinking water quality standards, Process (II) was adopted by the Chen-Chin-Lake WTP. The processes include the preozonation, coagulation, sedimentation, pellet softening, rapid filtration, postozonation, and biological activated carbon. These treatment processes are expected to achieve the following goals: (1) reduce the hardness from 240 to $150 \mathrm{mg} / \mathrm{L}$; (2) replace prechlorination and postchlorination with ozonation; and (3) remove taste and odor by the biological activated carbon filtration process. After adopting these processes, a recent study indicates that the water meets the drinking water quality standards (shown in Table 6).

\section{Conclusions}

Three demonstration plants were performed in accordance with the SWIPR. The existing WTPs may be evaluated and modified based on the concept of CPE. In the Da-Nan WTP (Type 1), a tracer test with sodium chloride revealed that a hydraulic jump should be installed to replace the existing mixer in the rapid mixing tank to provide better mixing. To reduce turbidity in rapid
Table 6. Major Quality Parameters after Completion of Upgrading Project in the Chen-Chin-Lake WTP

\begin{tabular}{|c|c|c|}
\hline Water quality parameters & Design water quality & $\begin{array}{c}\text { Current drinking } \\
\text { water quality } \\
\text { standards } \\
\text { (July 2005) }\end{array}$ \\
\hline $\mathrm{pH}$ & $6.0-8.5$ & $6.0-8.5$ \\
\hline Color (PCU) & 3 & 5 \\
\hline Odor (TON) & 1 & 3 \\
\hline Free residual chlorine $(\mathrm{mg} / \mathrm{L})$ & $0.5-1.0$ & $0.2-1.0$ \\
\hline Turbidity (NTU) & $\begin{array}{c}0.2 \\
\text { (95\% of the time) } \\
0.3 \\
\text { (100\% of the time) }\end{array}$ & 2 \\
\hline Ammonia (mg/L) & 0.008 & 0.1 \\
\hline THM (mg/L) & 0.04 & 0.08 \\
\hline HAA (mg/L) & 0.03 & - \\
\hline Bromate (mg/L) & 0.008 & 0.01 \\
\hline Total hardness $\left(\mathrm{mg} / \mathrm{L}\right.$ as $\left.\mathrm{CaCO}_{3}\right)$ & 150 & 300 \\
\hline Total dissolved solids (mg/L) & 500 & 500 \\
\hline Total coliforms (CFU/100 mL) & 0 & 6 \\
\hline $\mathrm{AOC}(\mu \mathrm{g}$ acetate- $\mathrm{C}$ eq/L) & 50 & - \\
\hline
\end{tabular}

filtration effluent, the filter media is examined and replaced periodically. With these minor modifications, the quality of the treated water will improve and meet the drinking water quality standards.

The disinfection performance curves generated from the disinfection kinetic model for the Liu-Du WTP (Type 2) may be used as guidelines for improving the operation of the chlorine contact chamber. The performance code also may be used as a reference to a design engineer to determine the appropriate number of baffles for upgrading the chlorine chamber performance at the existing WTP. With this model development, the application of chlorine at about $1.0 \mathrm{mg} / \mathrm{L}$ level at Liu-Du WTP is the most cost effective method to minimize THM formation, maximize disinfection efficiency, and maintain an acceptable level of residual chlorine $(0.2-1.0 \mathrm{mg} / \mathrm{L})$ and THMs $(80 \mu \mathrm{g} / \mathrm{L})$.

For the Chen-Chin-Lake WTP (Type 3), advanced water treat-

Table 5. Comparison of Clean Water Quality and the Aspects of Engineering, Environment, and Economics for Different Processes in the Chen-Chin-Lake Pilot Plants

\begin{tabular}{|c|c|c|c|c|c|}
\hline \multirow[b]{2}{*}{ Parameters } & & \multirow[b]{2}{*}{ Raw water } & \multicolumn{3}{|c|}{ Clean water } \\
\hline & & & Process (I) & Process (II) & Process (III) \\
\hline \multirow[t]{6}{*}{ Water quality } & Turbidity (NTU) & NA & 0.20 & 0.07 & 0.03 \\
\hline & NPDOC (mg/L) & 1.10 & 0.90 & 0.29 & 0.17 \\
\hline & $\mathrm{AOC}(\mu \mathrm{g}$ acetate-C eq/L) & NA & 25 & 13 & 4 \\
\hline & Total hardness (mg/L) & 238 & 230 & 109 & 18 \\
\hline & TTHM $(\mu \mathrm{g} / \mathrm{L})$ & NA & 8.4 & 0.7 & 0.3 \\
\hline & TTHMFP $(\mu \mathrm{g} / \mathrm{L})$ & 79.1 & 31.4 & ND & ND \\
\hline \multirow[t]{4}{*}{ Engineering } & Efficiency & - & Medium & High & High \\
\hline & Flexibility & - & Low & Medium & High \\
\hline & Reliability & - & Medium & High & High \\
\hline & Energy consumption & - & Low & Medium & High \\
\hline \multirow[t]{2}{*}{ Environment } & Environmental impact & - & Low & Medium & Medium \\
\hline & Water quality & - & Medium & High & High \\
\hline \multirow[t]{2}{*}{ Economics } & Installation cost & - & Low & High & High \\
\hline & Operation and maintenance cost & - & Low & Medium & High \\
\hline
\end{tabular}

Note: $\mathrm{NA}=$ not available; and $\mathrm{ND}=$ not detectable. 
ment processes, i.e., preozonation, coagulation, sedimentation, pellet softening, rapid filtration, postozonation, and BAC processes need to be constructed. After completing the installation of the advanced treatment units, a study indicated the following goals were achieved: (1) reduction of the hardness of finished water from 240 to $150 \mathrm{mg} / \mathrm{L}$; (2) replacement of prechlorination and postchlorination with ozonation; and (3) removal of bad taste and odor by the biological activated carbon filtration process to meet the drinking water quality standards.

\section{Acknowledgments}

This research is supported by grants from the Taiwan EPA and Taiwan Water Company. Special thanks are extended to experts from the Taiwan water supply industry and professors from various universities for their valuable input.

\section{Notation}

The following symbols are used in this paper:

$b=$ disinfection coefficient $(\mathrm{mg} \mathrm{min} / \mathrm{L})$;

$C=$ effluent concentration $(\mathrm{mg} / \mathrm{L})$;

$C_{0}=$ influent concentration $(\mathrm{mg} / \mathrm{L})$;

$D_{L}=$ dispersion coefficient $\left(\mathrm{m}^{2} / \mathrm{min}\right)$;

$d=$ dimensionless molecular diffusion coefficient, dispersion index $\left(D_{L} / \mu L\right)$;

$E_{\theta}=$ dimensionless concentration $\left(C / C_{0}\right)$;

$k=$ nonideality coefficient in dispersion model;

$k_{1}=$ rate constant of chlorination with respect to chlorine ( $\mathrm{L} / \mathrm{mg} \min )$;

$k_{2}=$ rate constant of chlorination with respect to THMs formation $\left[(\mathrm{L} / \mathrm{mg})^{m} \mathrm{~min}\right]$;

$L=$ total length of flow pass-through baffled rectangular reactor $(\mathrm{m})$;

$m=$ order of chlorination reaction with respect to THMs formation;

$N=$ number of surviving microorganisms;

$N_{0}=$ number of microorganisms in influent water;

$n=$ disinfection coefficient;

$T=$ theoretical residence time $(\mathrm{min})$;

$t=$ exit residence time $(\mathrm{min})$;

$W=$ channel width of baffled rectangular reactor $(\mathrm{m})$; and

$\theta=$ dimensionless residence time $(t / T)$.

\section{References}

American Public Health Association (APHA). (1998). Standard methods for the examination of water and wastewater, 20th Ed., Washington, D.C.

Chang, E. E., Chiang, P. C., Lin, Y. L., and Tsai, H. P. (2005). "Evaluation of source water quality standards for total coliforms, TOC, and COD in Taiwan." Pract. Period. Hazard. Toxic Radioact. Waste Manage., 9(3), 193-203.

Chiang, P. C., Chang, E. E., Ko, Y. W., and Lou, J. C. (1997). "Balancing disinfection efficiency and THM formation during chlorination: Theoretical considerations." Can. J. Chem. Eng., 75(5), 892-898.

EEC. (1975). "Council directives: Concerning the quality required of surface water intended for the abstraction of drinking water in the Member States." 75/440, Official Journal of the European Communities.

Environmental Health Directorate (EHD). (2003). "Summary of guidelines for Canadian drinking water quality." Prepared by the FederalProvincial Subcommittee on Drinking Water of the Federal-Provincial Committee of Environmental and Occupational Health.

Lou, J. C., and Chiang, P. C. (1994). "A study of trihalomethane formation in a water distribution system." Hazard. Waste Hazard. Mater. 11(2), 333-343.

Morris, J., and Baum, B. (1977). "Precursors and mechanisms of haloform formation in the chlorination of water supplies." Galinberg Conf.

National Health and Medical Research Council (NHMRC). (1996). "Australian drinking water guidelines." Agricultural and Resource Management Council of Australia and New Zealand, Commonwealth of Australia.

Qualls, R. G., and Johnson, J. D. (1983). "Kinetics of the short-term consumption of chlorine by fulvic-acid." Environ. Sci. Technol., 17(11), 692-698.

Rook, J. J. (1977). "Chlorination reactions of fulvic acids in naturalwaters." Environ. Sci. Technol., 11(5), 478-482.

Taiwan Environmental Protection Administration (Taiwan EPA). (2000). "Investigation of TOC, COD and total coliforms in source water and evaluation of source water quality standards." EPA-89-J102-031093, Taiwan, Republic of China.

United States Environmental Protection Agency (USEPA). (1998). "Handbook: Optimizing water treatment plant performance using the composite correction program." EPA/625/6-91/027, Cincinnati.

United States Environmental Protection Agency (USEPA). (2004). "2004 edition of the drinking water standards and health advisories." EPA/ 822/R-04/005, Washington, D.C.

Yeh, J. H., Hsu, M. H., Chang, E. E., and Huang, C. P. (1997). "Development of statute governing drinking water and strategic plan for drinking water research in ROC." Proc., 3rd Int. Workshop on Drinking Water Quality Management and Treatment Technology, Taiwan, Republic of China. 